\title{
Remote cerebellar hemorrhage as a complication of lumbar spine surgery
}

\author{
Cheryl Hui Shan Lim ${ }^{1 *}$, Parag Ratnakar Salkade ${ }^{1}$, Assimta Cynthia Peter ${ }^{1}$ \\ 1. Department of Radiology, Sengkang General Hospital, Singapore, Singapore \\ * Correspondence: Cheryl Hui Shan Lim, Department of Radiology, Sengkang General Hospital, 110 Sengkang East Way, Singapore \\ 544886, Singapore \\ ( $\triangle$ Cheryl.lim.hs@gmail.com)
}

Radiology Case. 2020 Feb; 14(2):1-11 :: $\quad$ DOI: 10.3941/jrcr.v14i2.3844

\begin{abstract}
Remote cerebellar hemorrhage ( $\mathrm{RCH})$ is a rare yet potentially fatal complication of supratentorial and spinal surgery, where there has been either intentional or accidental breach of the dura. We present a case of $\mathrm{RCH}$ following a L4-5 decompression laminectomy complicated by an intraoperative dural tear which was detected and repaired at the time of surgery. Despite prompt intra-operative repair of the dura, there was persistent cerebrospinal fluid leak as evidenced by a high subfascial epidural drain output which resulted in bilateral intraparenchymal cerebellar hemorrhage. The patient was managed conservatively and recovered without neurological deficits.
\end{abstract}

\section{CASE REPORT}

\section{CASE REPORT}

A 74-year-old Chinese male presented with one year of low back pain, bilateral S1 radiculopathy and bilateral lower limb weakness. He had a slow and unsteady gait as well as a positive Romberg's test. His past medical history included adequately-controlled hypertension on a single antihypertensive (angiotensin converting enzyme (ACE) inhibitor), hyperlipidemia, prior bilateral total knee replacement and pneumatic retinopexy.

Pre-operative Magnetic Resonance Imaging (MRI) lumbar spine demonstrated grade 1 anterolisthesis of L4 over L5, without a pars defect. At the L4-5 level, there was diffuse disc bulge, facet joint arthropathy and ligamentum flavum thickening resulting in severe spinal canal stenosis and mild compression of the cauda equina. The spinal canal at L4-5 measured $10 \times 9 \mathrm{~mm}$ in axial dimensions.

For this he underwent elective posterior decompression laminectomy and interbody cage fusion. Decompression laminectomy was performed by high speed burr drilling and Kerrison rongeur resulting in an inadvertent lumbar dural tear over the left side at the L4-5 level. This was promptly repaired with Prolene, Duragen and Dura-seal (synthetic dural allograft). Dural repair check with Valsalva maneuver to 50
$\mathrm{mmHg}$ was satisfactory. A subfascial epidural drain was placed, and set to active suction.

Post-operatively, he was monitored in the general ward and not mobilized in view of the durotomy. On the first postoperative day he was noted to have new onset diplopia. Pre and post contrast Computed Tomography (CT) brain did not demonstrate intracranial abnormalities. On the second postoperative day, he complained of severe neck pain without neurological deficits and also developed paroxysmal atrial fibrillation (PAF). A CT pulmonary angiogram for PAF was performed which was negative for pulmonary embolism. He was started on a beta blocker (bisoprolol $2.5 \mathrm{mg} \mathrm{OD}$ ). No anticoagulation was prescribed. The atrial fibrillation resolved and his blood pressure remained stable without hypotension or hypertension. On the third post-operative day, his subfascial epidural drain output increased by $260 \mathrm{ml}$ within four hours and was more colorless, presumably containing more CSF. This raised the suspicion of a possible CSF leak and concerns of suction on the dural repair site. His subfascial epidural drain was changed from active suction to passive drainage. On the fifth post-operative day, he developed giddiness, slurred speech and visual hallucinations which were investigated with MRI brain for possible posterior circulation stroke. In addition, cessation of patient-controlled analgesia (PCA), Morphine resulted in resolution of the visual hallucinations. 
The MRI brain (Figures 1, 2, 3, 4) showed susceptibility artefacts on susceptibility weighted imaging (SWI) and T1w hyperintensities in bilateral cerebellar hemispheres associated with vasogenic edema and mild mass effect upon the cerebellar folia, 4 th ventricle and basal cisterns. There was no acute infarct, cerebellar tonsillar herniation, hydrocephalus or midline shift. Subsequent non-contrast CT brain performed six hours later re-demonstrated stable bilateral intraparenchymal cerebellar hemorrhages, (Figure 5), as well as the "zebra sign" with hyperdense subarachnoid blood within the cerebellar sulci, alternating with hypodense cerebellar parenchyma (Figure 5A, 5E). Vasogenic edema and associated mild mass effect were seen again. Considering that the patient did not have any other cause to account for hemorrhage (such as trauma or anti-coagulants or coagulopathy), cerebellar hemorrhages were attributed to remote bleed from intraoperative dural leak. As there were no significant secondary intracranial complications due to $\mathrm{RCH}$, such as tonsillar herniation, midline shift or hydrocephalus, the patient was managed conservatively. The CSF drain output declined and eventually stopped following which the subfascial epidural drain was removed on the sixth post-operative day.

The patient remained stable with no drop in his Glasgow Coma Score. There was improvement in his symptoms of neck pain and blurring of vision without development of new symptoms. He was allowed to proceed with physiotherapy and was able to ambulate with the aid of a quad stick by his discharge on the 16th post-operative day.

At one month follow up, there was complete resolution of his symptoms. Repeat non-contrast CT brain (Figure 6) showed improvement and reduction in the size, density and extent of the bilateral cerebellar hemorrhages. No gliosis or encephalomalacia was identified in the interim. The patient was subsequently discharged from neurosurgical follow up for the $\mathrm{RCH}$

\section{DISCUSSION}

$\mathrm{RCH}$ is defined as post-operative bleeding in the cerebellum which develops distant to the surgical site [1]. It is a rare complication that may occur following supratentorial craniotomy and spine surgery, and is potentially fatal [2].

\section{Etiology \& Demographics:}

The incidence of $\mathrm{RCH}$ is $0.08-0.6 \%$ following supratentorial craniotomies [3], [4]. It is presumably significantly less following spinal surgery [1], [5], [6]. RCH following spine surgery was first reported by Chadduck et al. in 1981 after cervical laminectomy, and has been noted with increasing frequency after spine surgery in the recent years [3]. A few cases of RCH following insertion of a lumboperitoneal shunt [5] and lumbar puncture [7] have also been reported. The difference in incidence may be due to under-reporting, as a fair number of $\mathrm{RCH}$ cases are asymptomatic, detected after routine post-operative neuroimaging for supratentorial surgeries. As neuroimaging is not routinely performed following spine surgery, only the symptomatic patients are diagnosed [6], [8], [9]. As such, all reported cases of $\mathrm{RCH}$ following spine surgery were symptomatic [4].

\section{Clinical \& Imaging Findings:}

Sturiale et al. performed the largest two-part review to date for RCH following supratentorial and spinal surgery [2], [4]. In this, they analyzed the data of 57 patients in 44 articles from 1981 to 2013, who developed $\mathrm{RCH}$ following spinal surgery [4].

They noted that the most common presenting complaint is that of reduced consciousness, altered mental state or delayed waking from anesthesia (47\%). Other symptoms can be grouped into cerebellar syndrome (such as ataxia, gait disturbances or incoordination), raised intracranial pressure (such as headache, nausea, vomiting or seizure, due to mass effect from the hemorrhage) or intracranial hypotension (due to brain sag, traction of cranial nerves resulting in visual field disturbances or diplopia) [2], [10], [11].

The onset of $\mathrm{RCH}$ following spine surgery was observed to be a mean of 60.6 hours, with majority of patients presenting within 24 hours $(42.1 \%)$ and $24-72$ hours $(40.3 \%)$ [4]. This is longer than that for patients after supratentorial surgery, with majority of the patients being symptomatic within 24 hours (80.4\%), of which $31.5 \%$ developed symptoms immediately after surgery [2]. This difference in onset / diagnosis may be partly attributed to the difficulty in assessment of gait disturbances in patients after recent spine surgery [9].

Neuroimaging is required for diagnosis of $\mathrm{RCH}$. The most commonly described appearance of $\mathrm{RCH}$ on $\mathrm{CT}$ is the "zebra sign" caused by subarachnoid hemorrhage, with an alternating striped pattern of hyperdense subarachnoid blood between hypodense cerebellar parenchyma, mimicking a zebra's coat [2], [6], [8], [10], [12], [13]. This was noted by Sturiale et al. to be seen in $42 \%$ of the cases [4]. Other patterns of cerebellar hemorrhage include intra-parenchymal hemorrhage, $(37.5 \%)$ and a mixed pattern (19.6\%) [4]. It may be unilateral (43.5\%), bilateral $(53.5 \%)$ or rarely in the midline [1]. Bilateral "zebra sign" is the most common presentation seen in $74 \%$ of cases analyzed by Sturiale et al. [2]. Dincer et al. evaluated CT and MRI imaging findings of patient's who developed $\mathrm{RCH}$ post supratentorial surgery. In their eight (of 983) patients who had positive imaging findings, they found that apart from the above described classical neuro-imaging findings (of "zebra sign" and intraparenchymal hemorrhage), there was a case of punctate folial hypointensity on MRI, and another case of intraventricular hemorrhage in the occipital horn [14]. They also noted a case of hemorrhage in an atypical location of the cerebellar tonsils [14]. They found MRI to be more sensitive than CT as it was able to demonstrate minor hemorrhage on susceptibility sensitive sequence before the patients became symptomatic and before they were apparent on CT [14]. They also noted that the MRI findings may persist for years beyond the $\mathrm{RCH}$ (at least up to five years, as per their follow up duration) [14]. 


\section{Risk Factors}

Several risk factors have been linked to $\mathrm{RCH}$. The most commonly observed risk factor is durotomy, intentionally or accidental, seen in $93 \%$ according to Sturiale et al. [4]. Of which, two thirds of the tears were noted and repaired, while the other third was occult, and only detected in the postoperative period. The presence of a subfascial drain was observed in $42 \%$, suggesting that a prolonged post-operative CSF leak may be riskier than an intra-operative leak which would have been promptly repaired [4]. In addition, they noted that approximately $25 \%$ of the patients had a history of previous spinal surgery, $15 \%$ had hypertension. Coagulopathies were seen in $10 \%$ and anti-coagulation medication in $7 \%$. As coagulation disorders, peri-operative CSF drainage, and hypertension were seen in less than one third of the cases, these risk factors were considered to play a relatively limited etiological role [4].

Struiale et al. noted that for infratentorial surgery, lumbar spine surgery (compared with cervical or thoracic spine surgery) was most noted to be associated with $\mathrm{RCH}$, especially if there was fusion or pedicle screw insertion [4]. More than half of the $\mathrm{RCH}$ patients had spinal canal decompression with instrumented fusion $(52.6 \%)$ while only $28 \%$ had laminectomy or discectomy alone. Overall, lumbosacral instrumentation was the most frequently reported in association with $\mathrm{RCH}$ [4]. This is likely due to the increased risk of occult dural tear which may precipitate a fistula [4]. As similar patterns of $\mathrm{RCH}$ are seen in both spinal and supratentorial surgeries with CSF leakage, it is believed that they should be of similar pathophysiology [4]. Although the exact pathophysiology of post-surgical $\mathrm{RCH}$ has not been established, most authors agree that $\mathrm{RCH}$ is a hemorrhage of venous etiology contributed by a peri-operative loss of CSF [1], [6], [10], [13], [15]-[20].

\section{Pathophysiology}

Friedman et al. postulated that CSF loss leads to changes in pressure gradient between the cranial and spinal compartments, precipitating downward sagging of the cerebellum. This causes resultant stretching, tearing and occlusion of the cerebellar veins (superior vermian veins and superior cerebellar vein which drain in to the deep venous system), resulting in a venous infarct and venous hemorrhage or direct hemorrhage [6], [13], [17], [18]. It is similar to the "sinking brain syndrome" proposed by Kelley et al., Yoshida et al. and Konig et al. suggested that $\mathrm{RCH}$ is related to the volume of CSF drained, while Choi et al. postulates that it may be the velocity of CSF drain in the peri-operative period, both which may be aggravated by negative pressure drainage [15], [19], [21]. Even with a watertight dural seal, postoperative negative pressure exerted by a subfascial drain may precipitate CSF loss between the stitches, leading to pressure shifts and hemorrhage [16].

Yoshida et al. explained that in the horizontal positioning of the patient, the cerebellar veins run along the tentorium and may be easily kinked by fluctuations in pressure gradients [15]. This is a theory supported by Konig et al. who postulated that removal of supratentorial masses increase venous pressure gradients between the supra and infra tentorial compartments.
The distribution of the hemorrhage at the superior aspect of the cerebellum, and bilateral distribution of hemorrhage favors this theory [16].

An arterial etiology is deemed less likely as that would tend to cause unilateral hemorrhage and cerebellar infarction [15], [16] . Furthermore, angiography performed by Yoshida et al. following $\mathrm{RCH}$ was negative [15].

\section{Treatment \& Prognosis:}

Prognosis is variable ranging from good outcome with no neurological deficit to death. Struiale et al. reported that majority of patients had a good prognosis, with $76.7 \%$ having a good Glasgow Outcome Score (GOS) at the time of discharge [4]. In particular, they noted better outcomes in studies published after 2001 (51\% versus 80\%), likely reflecting improvement in management [2].

Struiale et al. observed that poor outcome of $\mathrm{RCH}$ following spine surgeries were seen more frequently with an onset characterized by reduced consciousness and antiplatelet/ anticoagulation therapy - these were however not statistically significant in their multivariate analysis and not able to reliably predict a poor outcome [4]. The "zebra sign" pattern of $\mathrm{RCH}$ was noted more frequently in patients with good outcomes who had spinal or supratentorial surgeries.

Patient's with bilateral $\mathrm{RCH}$ and unilateral $\mathrm{RCH}$ had similar outcomes [4]. RCH complicated by hydrocephalus was seen in a third of cases [4]. Mortality was comparable for $\mathrm{RCH}$ following spine and supratentorial surgery at approximately $12 \%$ [1], [2], [4].

Majority of the patients were managed conservatively (49.1\%), $19.3 \%$ required placement of an extra-ventricular drain (EVD) due to symptomatic hydrocephalus, while $12.2 \%$ underwent suboccipital craniotomy and decompression due to significant mass effect on the brainstem and cerebellum [2], [4].

Currently, there are no established guidelines for management of post-operative $\mathrm{RCH}$. Authors have recommended preventative measures, such as avoidance of excessive CSF drainage and durotomy, peri-operative blood pressure control, and correction of coagulopathies [1], [2], [4], [21].

Clinical suspicion and early detection are critical. When patients present with neurological signs or symptoms suggestive of raised intracranial pressure following spine or supratentorial surgery, the drains should be checked for increased volumes of drained fluid (and possibly suction stopped) [21], [22]. Prompt evaluation with neuroimaging should be performed [1], [21].

Once $\mathrm{RCH}$ has been diagnosed, overall management is largely dependent on the size of the hemorrhage, resultant mass effect and complications. A search for dural leaks should be performed and sealed. If there is obstructive hydrocephalus, shunting of CSF should be performed with an extra- 
ventricular drain; and if there is massive mass effect, suboccipital decompressive craniotomy may be required to prevent herniation of the brainstem [1].

Other factors such as blood pressure and coagulation abnormalities should be controlled / corrected to prevent worsening of the hemorrhage [18].

\section{Differential Diagnoses:}

Apart from different causes of cerebellar hemorrhage (such as trauma or coagulopathies), other differentials include pseudo-subarachnoid hemorrhage (pseudo-SAH).

\section{(I) Infective Leptomeningitis}

Leptomeningitis is another cause of pseudo-SAH. Most patients tend to have a normal non-contrast CT brain, although purulent exudates in the CSF space may be hyperdense and mimic SAH. On MRI, these leptomeningeal proteinaceous exudates may be $\mathrm{T} 1 \mathrm{w}$ hyperintense, if evident. On post contrast imaging (CT and MRI brain) the breakdown of the blood brain barrier may cause leptomeningeal enhancement. [23] A clinical history of infective symptoms may be useful to differentiate this.

\section{(II) Infective Cerebellitis}

This may be due to viral infections caused by Measles morbillivirus, Varicella zoster virus, or Epstein barr virus, or other infectious agents such as Mycobacterium tuberculosis or Taenia solium (in neurocysticercosis). In severe cases, they may manifest as edema of the cerebellum, with positive restricted diffusion and contrast enhancement of the cerebellum and leptomeninges. These are usually bilateral in distribution (unilateral involvement is uncommon) though supratentorial grey and white matter involvement may also be present. Cerebellar intra-parenchymal granulomata may be seen in tuberculous infections and neurocysticercosis. [24]

\section{(III) Hypoxic-Ischemic Encephalopathy}

A history of cardiopulmonary collapse usually precedes this diagnosis.

On CT, "white cerebellum" sign is seen due to relative sparing of the cerebellum compared to diffuse edema and hypoattenuation of the cerebrum. Linear cortical hyperdensities seen in cortical laminar necrosis due to the accumulation of denatured protein in dying cells, may mimic hyperdense blood products (and is another cause for pseudo$\mathrm{SAH})$. As grey matter is sensitive to hypoxic injury, other features include loss of the normal grey-white matter differentiation of both the superficial cortical grey matter and the deep grey matter, as well as diffuse cerebral edema with sulcal effacement. [25]

On MRI, diffusion weighted images are the most sensitive and may detect changes as early as within a few hours. In the early subacute period ( 24 hours to two weeks), there will be pseudo-normalization of the diffusion weighted imaging abnormalities, and the $\mathrm{T} 2 \mathrm{w}$ imaging abnormalities become more apparent. After two weeks, cortical laminar necrosis will appear as linear cortical based $\mathrm{T} 1 \mathrm{w}$ hyperintensities (seen as early as a few days as sulcal FLAIR hyperintensities). [25], [26]

A history of cardio-pulmonary collapse, together with other imaging features in the cerebrum and grey matter will help to distinguish this diagnosis.

\section{(IV)Toxic-Metabolic Encephalopathy}

Toxic-metabolic encephalopathy may present as T2w/FLAIR hyperintensities affecting bilateral cerebellar hemispheres and dentate nuclei, with or without restricted diffusion abnormality. Watershed infarcts of the cerebellum may be seen and the deep grey matter or brainstem would also tend to be involved. A thorough history may identify the source such as drug-use (such as antibiotics, organic solvent ingestion or methadone poisoning) and there may be derangements in the patient's blood gas level/biochemistry. [24], [27]

\section{(V) Iatrogenic/Embolic material from surgical interventions}

With a history of prior or recent surgery in the vicinity of the neural axis, embolization of surgical material may be a consideration. This is more probable with cranial, spine or ophthalmic interventions. The appearance of surgical objects or materials may have a varied appearance on imaging. Materials with high atomic numbers will be dense on CT. Silicon (from ophthalmic injections) is dense on CT and demonstrates T1w hyperintensity which may mimic blood products. On MRI, silicon has variable T2w signal and chemical shift sequences may be useful in troubleshooting. [28], [29] Gas may appear as signal voids on all sequences of MRI and will be of gas density on CT. Metallic components will demonstrate blooming susceptibility artefact on MRI and will be of metallic density on CT. [30]

\section{TEACHING POINT}

Remote cerebellar hemorrhage $(\mathrm{RCH})$ should be a diagnostic consideration for new onset central neurological symptoms following a lumbar spine surgery. "Zebra sign" for subarachnoid hemorrhage at the superior aspect of the cerebellum is an imaging finding. In majority of the cases, $\mathrm{RCH}$ has a self-limiting course with good prognosis.

\section{REFERENCES}

1. Brockmann M, Groden C. Remote cerebellar hemorrhage: A review. The Cerebellum. Mar 2006;5(1):64-68. PMID: 16527766

2. Sturiale CL, Rossetto M, Ermani M, Volpin F, Baro V, Milanese L, et al. Remote cerebellar hemorrhage after supratentorial procedures (part 1): A systematic review. Neurosurg Rev. Oct 2015;39(4):565-573. PMID: 26846668

3. Chadduck WM. Cerebellar Hemorrhage Complicating Cervical Laminectomy. Neurosurgery. Aug 1981;9(2):185189. PMID: 7266820 
4. Sturiale CL, Rossetto M, Ermani M, Baro V, Volpin F, Milanese L, et al. Remote cerebellar hemorrhage after spinal procedures (part 2): a systematic review. Neurosurg Rev. Jul 2016;39(3):369-376. PMID: 26627110

5. Sasani M, Sasani H, Ozer AF. Bilateral late remote cerebellar hemorrhage as a complication of a lumbo-peritoneal shunt applied after spinal arteriovenous malformation surgery. J Spinal Cord Med. 2010;33(1):77-79. PMID: 20397448

6. Friedman JA, Ecker RD, Piepgras DG, Duke DA. Cerebellar Hemorrhage after Spinal Surgery: Report of Two Cases and Literature Review. Neurosurgery. Jun 2002;50(6):1361-1364. PMID: 11846932

7. Nakata R, Motomura M, Morikawa M, Yoshimura T, Kawakami A. Remote cerebellar hemorrhage after lumbar puncture in herpes simplex encephalitis. Neurol Clin Neurosci. Nov 2015;3(6):229-231. ISSN: 20494173

8. Morofuji Y, Tsunoda K, Takeshita T, Hayashi K, Kitagawa $\mathrm{N}$, Suyama K, et al. Remote cerebellar hemorrhage following thoracic spinal surgery: Case report. Neurol MedicoChirurgica. 2009;49(3):117-119. PMID: 19318737

9. You S-H, Son KR, Lee NJ, Suh J-K. Remote Cerebral and Cerebellar Hemorrhage after Massive Cerebrospinal Fluid Leakage. J Korean Neurosurg Soc. 2012;51(4):240-243. PMID: 22737308

10. Amini A, Osborn AG, McCall TD, Couldwell WT. Remote cerebellar hemorrhage. AJNR Am J Neuroradiol. Feb 2006;27(2):387-390. PMID: 16484416

11. Naveed MA, Mangla R, Idrees H, Mehta RI. Remote Cerebellar Haemorrhage: A Potential Iatrogenic Complication of Spinal Surgery. Case Rep Neurol Med. Sep 2018;2018:1-4. PMID: 30305969

12. Brockmann MA, Nowak G, Reusche E, Russlies M, Petersen D. Zebra sign: cerebellar bleeding pattern characteristic of cerebrospinal fluid loss. J Neurosurg. Jun 2005;102(6):1159-1162. PMID: 16028781

13. Huang $\mathrm{PH}, \mathrm{Wu}$ JC, Cheng $\mathrm{H}$, Shih $\mathrm{YH}$, Huang WC. Remote cerebellar hemorrhage after cervical spinal surgery. J Chinese Med Assoc. 2013;76(10):593-598. PMID: 23746536

14. Dincer A, Özcan Ü, Kaya D, Usseli MI, Erzen C, Pamir MN. Asymptomatic remote cerebellar hemorrhage: CT and MRI findings. Cerebellum. Dec 2012;11(4):880-886. PMID: 22249914

15. Yoshida S, Yonekawa Y, Yamashita K, Ihara I, Morooka Y. Cerebellar Hemorrhage After Supratentorial Craniotomy. Neurol Med Chir (Tokyo). 1990;30(10):738-743. PMID: 1708447

16. Honegger J, Zentner J, Spreer J, Carmona H, SchulzeBonhage A. Cerebellar hemorrhage arising prospectively as a complication of supratentorial surgery: a retrospective study. J Neurosurg. Feb 2002;96(2):248-254. PMID: 11838798
17. Haller JM, Calvert G, Spiker WR, Brodke DS, Lawrence BD. Remote Cerebellar Hemorrhage after Revision Lumbar Spine Surgery. Glob Spine J. Dec 2015;5(6):535-537. PMID: 26682108

18. Friedman JA, Piepgras DG, Duke DA, McClelland RL, Bechtle PS, Maher CO, et al. Remote Cerebellar Hemorrhage after Supratentorial Surgery. Neurosurgery. Dec 2001;49(6):1327-1340. PMID: 11846932

19. König A, Laas R, Herrmann HD. Cerebellar haemorrhage as a complication after supratentorial craniotomy. Acta Neurochir (Wien). 1987;88(3-4):104-108. PMID: 3687495

20. Toczek MT, Morrell MJ, Silverberg GA, Lowe GM. Cerebellar hemorrhage complicating temporal lobectomy. J Neurosurg. Oct 1996;85(4):718-722. PMID: 8814184

21. Choi BW, Lee SM, Yoon MG, Moon MS. Cerebellar Hemorrhage after Posterior Lumbar Decompression and Interbody Fusion Complicated by Dural Tear: A Case Report. J Korean Soc Spine Surg. 2014;21(4):183-188. pISSN: 20934378

22. Suzuki M, Kobayashi T, Miyakoshi N, Abe E, Abe T, Shimada Y. Remote cerebellar hemorrhage following thoracic spinal surgery of an intradural extramedullary tumor: A case report. J Med Case Rep. Mar 2015;9(1):68. PMID: 25889850

23. Mendelsohn DB, Moss ML, Chason DP, Muphree S, Casey S. Acute purulent leptomeningitis mimicking subarachnoid hemorrhage on CT. J Comput Assist Tomogr. 1994;18(1):126-128. PMID: 8282861

24. Arora R. Imaging spectrum of cerebellar pathologies: a pictorial essay. Polish J Radiol. 2015;80:142-150. PMID: 25806100

25. Huang BY, Castillo M. Hypoxic-ischemic brain injury: imaging findings from birth to adulthood. Radiographics. Mar 2008;28(2):417-439; quiz 617. PMID: 18349449

26. Rabinstein AA, Resnick SJ. Practical neuroimaging in stroke?: a case-based approach. Saunders/Elsevier; 2009. 401 p. ISBN: 0750675373

27. Mills F, MacLennan SC, Devile CJ, Saunders DE. Severe cerebellitis following methadone poisoning. Pediatr Radiol. Feb 2008;38(2):227-229. PMID: 17952429

28. Fangtian D, Rongping D, Lin Z, Weihong Y. Migration of intraocular silicone into the cerebral ventricles. Am J Ophthalmol. Jul 2005;140(1):156-158. PMID: 16038670

29. Kuhn F, Kover F, Szabo I, Mester V. Intracranial migration of silicone oil from an eye with optic pit. Graefe's Arch Clin Exp Ophthalmol. Oct 2006;244(10):1360-1362. PMID: 16523301

30. Wolfson KA, Seeger LL, Kadell BM, Eckardt JJ. Imaging of Surgical Paraphernalia: What Belongs in the Patient and What Does Not. RadioGraphics. Nov 2000;20(6):1665-1673. PMID: 11112821 


\section{FIGURES}

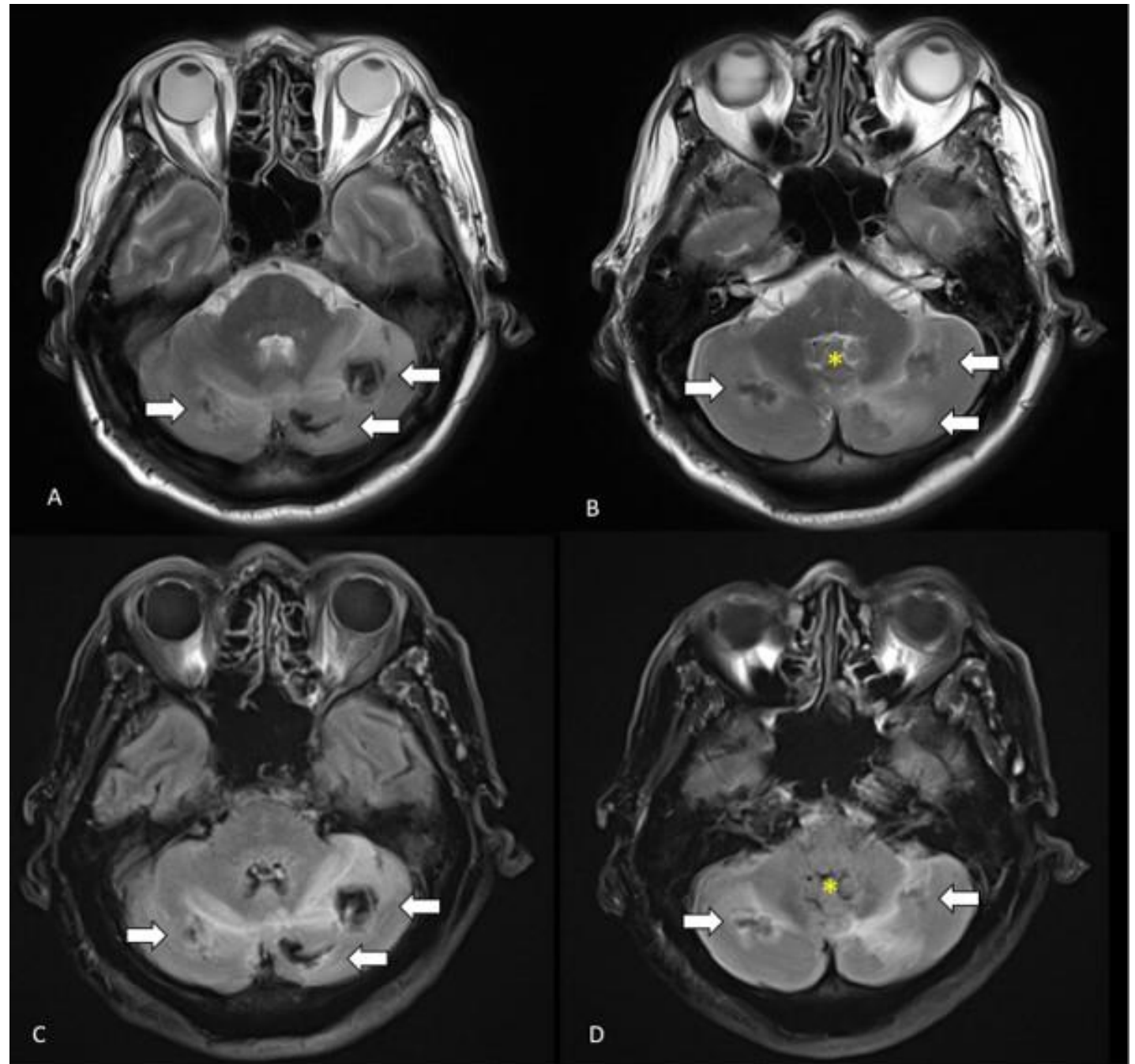

Figure 1: 74-year old man with remote cerebellar hemorrhage after spinal surgery.

Findings: MRI brain performed on the post-operative day 5 with axial T2w (A-B), axial FLAIR (C-D), shows subacute hemorrhage in bilateral cerebellar hemispheres (white arrow), with vasogenic edema and effacement of cerebellar folia. Mild mass effect on the 4th ventricle (yellow asterisk) and basal cisterns.

Technique: MRI, Siemens Skyra, 3T; (A-B): Axial T2w (non-contrast): TR 2560 ms, TE 100 ms, slice thickness 5 mm; (C-D): Axial FLAIR: TR 7300 ms, TE 2262 ms, TI 132 ms, slice thickness 5 mm 


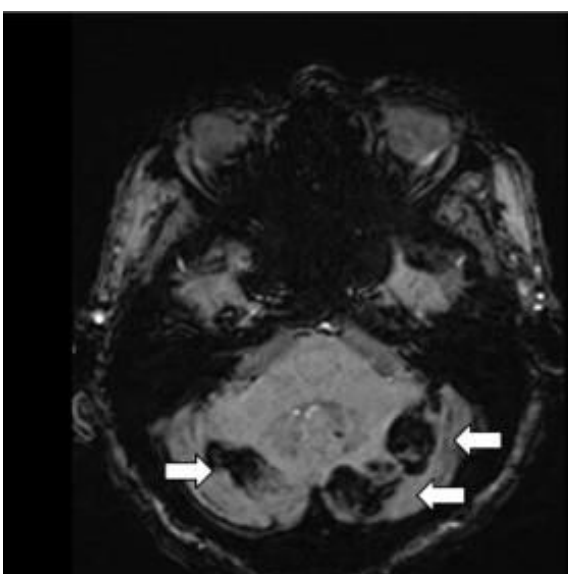

A

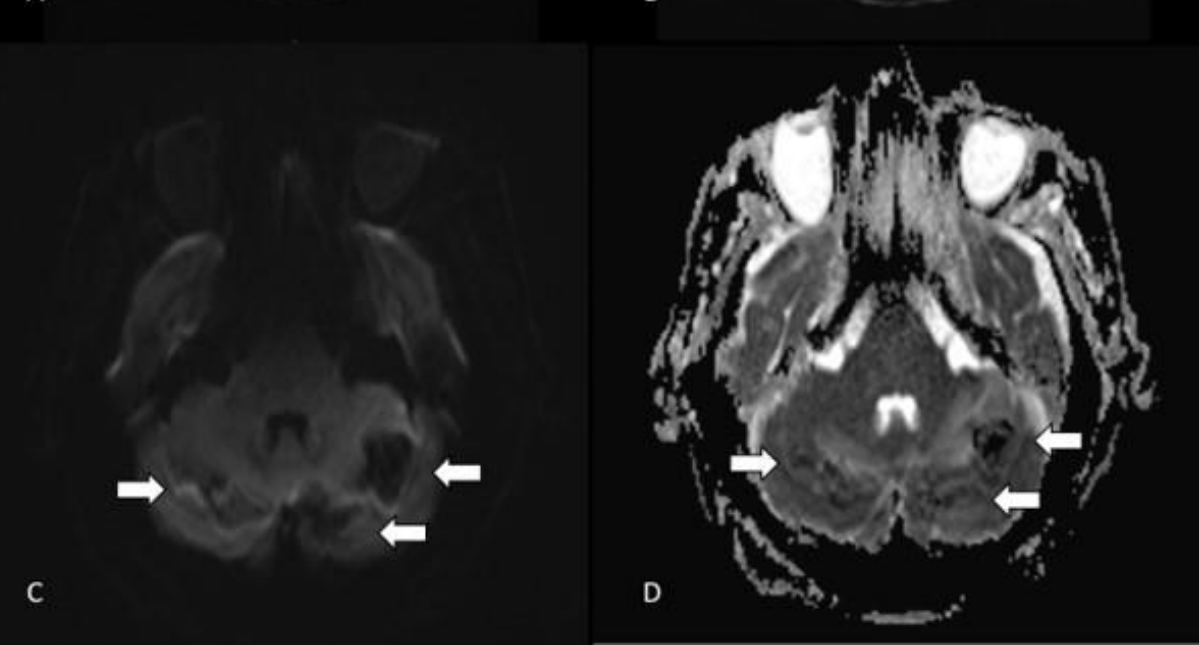

Figure 2: 74-year old man with remote cerebellar hemorrhage after spinal surgery.

Findings: MRI brain performed on the post-operative day 5 with axial SWI (A-B), DWI (C), ADC (D) shows subacute hemorrhage in bilateral cerebellar hemispheres (white arrow).

Technique: MRI, Siemens Skyra, 3T; (A-B) Axial SWI: TR27 ms, TE 20 ms, slice thickness 5 mm; (C) Axial DWI: TR 5900 ms, TE 96 ms, slice thickness 5 mm; (D) ADC: TR 5900 ms, TE 96 ms, slice thickness $5 \mathrm{~mm}$

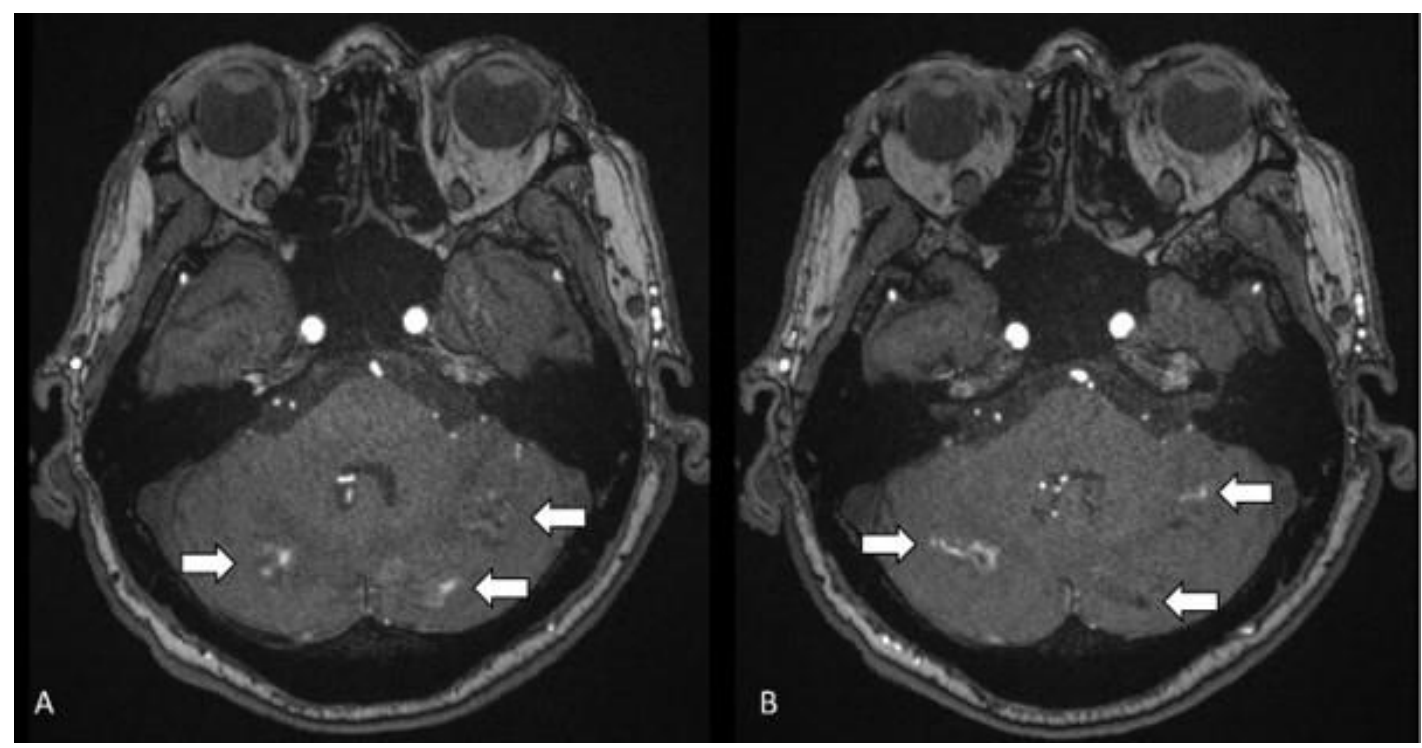

Figure 3: 74-year old man with remote cerebellar hemorrhage after spinal surgery.

Findings: MRI brain performed on the post-operative day 5 with TOF (A-B) shows subacute hemorrhage in bilateral cerebellar hemispheres (white arrow).

Technique: MRI, Siemens Skyra, 3T; (A-B) TOF: TR $21 \mathrm{~ms}$, TE $3.43 \mathrm{~ms}$, slice thickness $0.5 \mathrm{~mm}$

Radiology Case. 2020 Feb; 14(2):1-11 


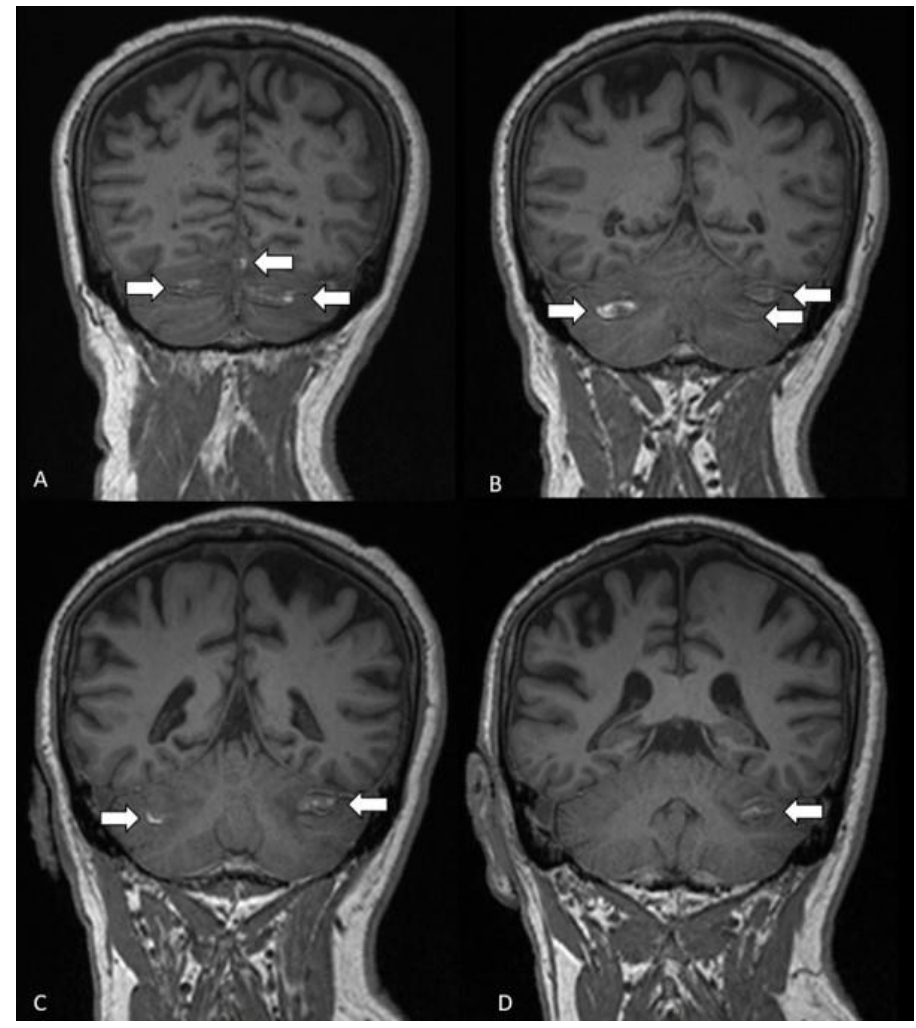

Figure 4: 74-year old man with remote cerebellar hemorrhage after spinal surgery.

Findings: MRI brain performed on the post-operative day 5 with coronal T1w from posterior to anterior (A-D) shows subacute hemorrhage in bilateral cerebellar hemispheres (white arrow).

Technique: MRI, Siemens Skyra, 3T

(A-D) Coronal T1w from posterior to anterior (non-contrast): TR $1700 \mathrm{~ms}$, TE 900, TI $2.43 \mathrm{~ms}$, slice thickness $5 \mathrm{~mm}$

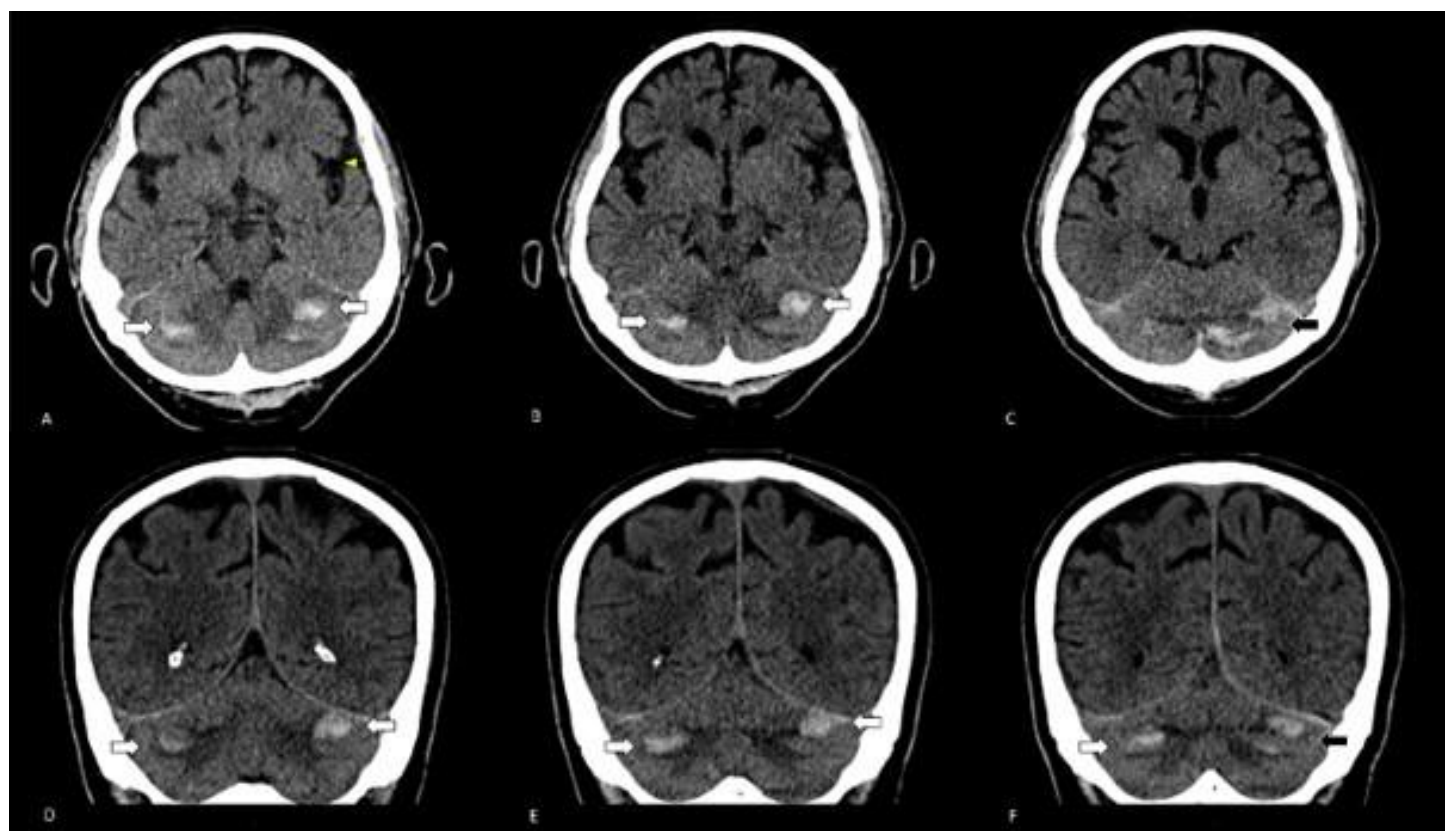

Figure 5: 74-year old man with remote cerebellar hemorrhage after spinal surgery.

Findings: Non-contrast CT brain 6 hours after initial diagnosis in axial (A-C, from inferior to superior) and coronal (D-E, from anterior to posterior) shows cerebellar hemorrhage of mixed pattern - intraparenchymal hemorrhage (white arrows) and zebra pattern of subarachnoid hemorrhage (black arrow), with surrounding vasogenic edema. Mild mass effect upon the fourth ventricle and basal cisterns is noted. A pocket of intra-cranial gas in the left sylvian fissure is seen (yellow arrow head).

Techniques: Philips iCT 256 scanner, $301 \mathrm{mAs}, 120 \mathrm{kV}$; (A-C): Axial, non-contrast, slice thickness 3 mm; (D-F): Coronal noncontrast, slice thickness $3 \mathrm{~mm}$ 


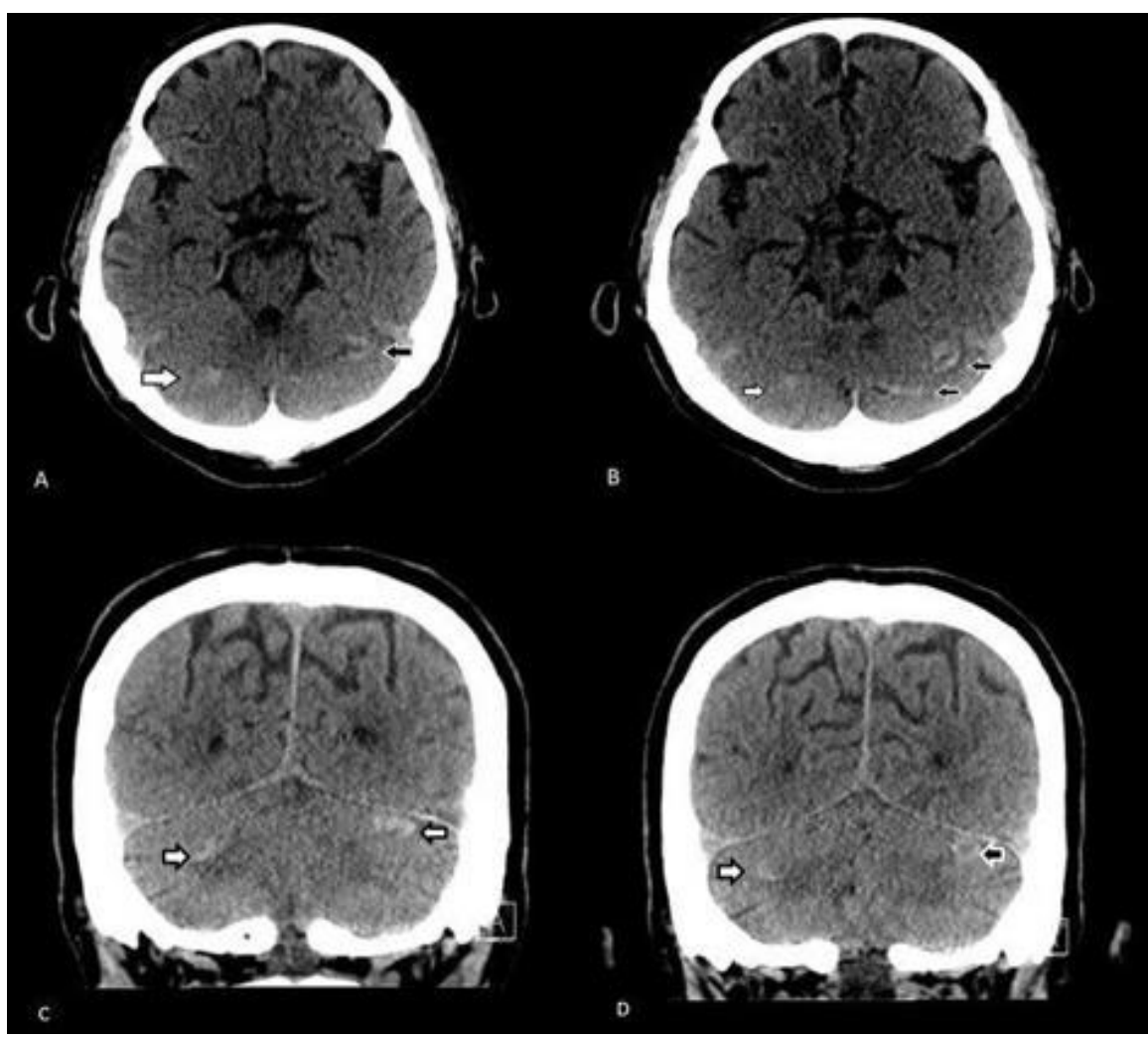

Figure 6: 74-year old man with remote cerebellar hemorrhage after spinal surgery.

Findings: Follow up non-contrast CT brain two weeks after initial diagnosis, in axial (A-B, from inferior to superior, and coronal (C-D, from anterior to posterior), demonstrates temporal evolution and decrease in size of hemorrhage in bilateral cerebellar hemispheres - Intraparenchymal hemorrhage (white arrow) and zebra pattern of subarachnoid hemorrhage (black arrow), with improvement in edema and mass effect.

Techniques: Siemen Somatom Definition Flash CT scanner; (A-B): Axial non-contrast, slice thickness 3 mm; (C-D): Coronal non-contrast, slice thickness $3 \mathrm{~mm}$

\begin{tabular}{|c|c|}
\hline Etiology & $\begin{array}{l}\text { Probably related to dural breach, CSF leak related to surgery leading to inferior sagging of the cerebellum, } \\
\text { compression of the superior cerebellar veins leading to venous hypertension and venous hemorrhage, or } \\
\text { shearing of the superior cerebellar veins leading to direct hemorrhage. }\end{array}$ \\
\hline Incidence & 0.08-0.6 \% following supratentorial surgery, and presumably significantly less following spine surgery. \\
\hline Gender ratio & Male: Female $=2: 3$ \\
\hline Age predilection & Mean age $57.6+/-14$ years \\
\hline $\begin{array}{l}\text { Associated } \\
\text { procedures }\end{array}$ & $\begin{array}{l}\text { Most frequently reported in spinal canal decompression with instrumented procedures on the lumbosacral } \\
\text { spine. }\end{array}$ \\
\hline Risk factors & $\begin{array}{l}\text { Dural breach } \\
\text { Subfascial drain } \\
\text { Instrumented procedures }\end{array}$ \\
\hline Onset & $\begin{array}{l}\text { Mean of } 60 \text { hours post-surgery. } \\
\text { Majority presents within } 72 \text { hours. }\end{array}$ \\
\hline Symptoms & $\begin{array}{l}\text { Reduced conscious or delayed waking from anesthesia, } \\
\text { Cerebellar signs, } \\
\text { Symptoms of intracranial hypertension or hypotension. }\end{array}$ \\
\hline Treatment & $\begin{array}{l}\text { Dependent on secondary intracranial complications (e.g.: significant mass effect, hydrocephalus or } \\
\text { herniation). } \\
\text { - } \\
\text { - } \quad \text { Conservative } \\
\text { - } \quad \text { Exb-occipital decompression craniotomy (to alleviate mass effect) } \\
\text { Extra-ventricular drain (for hydrocephalus) }\end{array}$ \\
\hline Prognosis & Good, as majority of the cases are self-limiting. \\
\hline Imaging findings & $\begin{array}{l}\text { "Zebra sign" subarachnoid hemorrhage in the superior cerebellum, intraparenchymal hematoma or mixed } \\
\text { picture. }\end{array}$ \\
\hline
\end{tabular}

Table 1: Summary table for remote cerebellar hemorrhage 


\begin{tabular}{|c|c|c|c|}
\hline \multirow[t]{2}{*}{ Differential Diagnosis } & \multicolumn{2}{|l|}{ Imaging Features } & \multirow[t]{2}{*}{ Clinical Presentation } \\
\hline & CT & MRI & \\
\hline $\begin{array}{l}\text { Infective } \\
\text { Leptomeningitis }\end{array}$ & $\begin{array}{l}\text { - Usually unremarkable } \\
\text { - Leptomeningeal hyperdensity, } \\
\text { may be nodular }\end{array}$ & $\begin{array}{l}\text { - Sulcal T2w/FLAIR hyperintensity } \\
\text { - Leptomeningeal enhancement }\end{array}$ & - Infective symptoms \\
\hline Infective Cerebellitis & $\begin{array}{l}\text { - Unremarkable } \\
\text { - Cerebellar edema }\end{array}$ & $\begin{array}{l}\text { - Swelling/edema of bilateral } \\
\text { cerebellar hemispheres } \\
\text { - Restricted diffusion and contrast } \\
\text { enhancement of the cerebellum and } \\
\text { leptomeninges } \\
\text { - Intra-parenchymal granulomas } \\
\text { (tuberculosis and neurocysticercosis) } \\
\text { - May also involved supratentorial } \\
\text { grey and white matter }\end{array}$ & - Infective symptoms \\
\hline $\begin{array}{l}\text { Hypoxic-Ischemic } \\
\text { Encephalopathy }\end{array}$ & $\begin{array}{l}\text { - Relative hyperdense } \\
\text { cerebellum / "White } \\
\text { cerebellum" } \\
\text { - Hyperdensity in basal cisterns } \\
\text { and sylvian fissure } \\
\text { - Cortical hyperdensity in } \\
\text { cortical laminal necrosis } \\
\text { - Loss of grey white matter } \\
\text { differentiation (deep and } \\
\text { superficial grey matter) } \\
\text { - Cerebral edema and sulcal } \\
\text { effacement }\end{array}$ & $\begin{array}{l}\text { - Grey matter structures affected } \\
\text { (basal ganglia, thalami, brain stem, } \\
\text { cortex) } \\
\text { - Restricted diffusion occurs early } \\
\text { with pseudonormalisation in } 2 \\
\text { weeks. } \\
\text { - Sulcal FLAIR hyperintensities in } \\
\text { cortical lamina necrosis (within a } \\
\text { few days) } \\
\text { - Cortical T1w hyperintensities in } \\
\text { cortical laminar necrosis }\end{array}$ & $\begin{array}{l}\text { - Cardio-pulmonary } \\
\text { collapse }\end{array}$ \\
\hline $\begin{array}{l}\text { Toxic-Metabolic } \\
\text { Encephalopathy }\end{array}$ & - Usually unremarkable & $\begin{array}{l}\text { - } \text { Bilateral } \\
\text { - Symmetrical involvement of the } \\
\text { dentate nuclei and cerebellum, } \\
\text { brainstem and deep grey matter } \\
\text { - T2w/FLAIR hyperintensity } \\
\text { - Restricted diffusion abnormality } \\
\text { - Diffuse cerebellar swelling } \\
\text { - Watershed infarcts in bilateral } \\
\text { cerebellar hemispheres }\end{array}$ & $\begin{array}{l}\text { - History of exposure } \\
\text { to toxins or drugs } \\
\text { - Blood gas / serum } \\
\text { biochemistry } \\
\text { abnormalities }\end{array}$ \\
\hline $\begin{array}{l}\text { Iatrogenic/Embolic } \\
\text { material from surgical } \\
\text { intervention }\end{array}$ & $\begin{array}{l}\text { - Subarachnoid space or } \\
\text { intraventricular } \\
\text { - Silicon oil }>90 \mathrm{HU} \text {, at the } \\
\text { anti-dependent aspects } \\
\text { - Air <-1000 HU, at the anti- } \\
\text { dependent aspects. } \\
\text { - Metallic density > } 2000 \mathrm{HU}\end{array}$ & $\begin{array}{l}\text { - Silicon oil: T1w hyperintense, T2w } \\
\text { signal variable, positive chemical } \\
\text { shift artefact. May have similar } \\
\text { signal to the treated globe } \\
\text { - Air: Signal void on all sequences } \\
\text { - Metallic densities or materials with } \\
\text { high atomic number: Susceptibility } \\
\text { blooming artefact, more pronounced } \\
\text { in the SWI sequences }\end{array}$ & $\begin{array}{l}\text { - Prior cranial, spine } \\
\text { or ophthalmic } \\
\text { intervention }\end{array}$ \\
\hline
\end{tabular}

Table 2: Differential diagnosis table for remote cerebellar hemorrhage 


\section{ABBREVIATIONS}

$\mathrm{ACE}=$ Angiotensin converting enzyme

$\mathrm{ADC}=$ Apparent diffusion coefficient

$\mathrm{CSF}=$ Cerebrospinal fluid

$\mathrm{CT}=$ Computed tomography

DWI $=$ Diffusion weighted imaging

EVD $=$ Extra-ventricular drain

FLAIR = Fluid-attenuated inversion recovery

HU $=$ Hounsfield unit

MRI = Magnetic resonance imaging

$\mathrm{PAF}=$ Paroxysmal atrial fibrillation

$\mathrm{RCH}=$ Remote cerebellar hemorrhage

SAH $=$ Subarachnoid hemorrhage

SWI = Susceptibility weighted imaging

$\mathrm{T} 1 \mathrm{w}=\mathrm{T} 1$-weighted

$\mathrm{T} 2 \mathrm{w}=\mathrm{T} 2$-weighted

$\mathrm{TOF}=$ Time of flight

\section{KEYWORDS}

Remote cerebellar hemorrhage; decompression laminectomy complication; spinal surgery complication; Zebra sign

\section{ACKNOWLEDGEMENTS}

Ms Umairah Binte Abdul Majeed

\section{Online access}

This publication is online available at:

www.radiologycases.com/index.php/radiologycases/article/view/3844

\section{Peer discussion}

Discuss this manuscript in our protected discussion forum at: www.radiolopolis.com/forums/JRCR

\section{Interactivity}

This publication is available as an interactive article with scroll, window/level, magnify and more features.

Available online at www.RadiologyCases.com

\section{Published by EduRad}

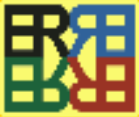

www.EduRad.org 